\title{
Characterizations of TIG welded joints of unalloyed commercially pure Titanium Gr-2 for weld process parameters
}

\author{
H. S. Patil, D. C. Patel \\ Mechanical Department, GIDC Degree Engineering College, Abrama, Gujarat, India \\ hspatil28@gmail.com,pateldcp@gmail.com \\ C. S. Patil \\ Mechanical Department, S. S. Agrawal Institute of Engineering \& Technology, Navsari, Gujarat, India \\ chetan27051985@gmail.com
}

\begin{abstract}
Titanium and titanium alloys can be welded by gas tungsten arc, gas metal arc, plasma arc and electron beam welding processes. Titanium material is a reactive metal and is sensitive to embrittlement by oxygen, nitrogen, and hydrogen gas at elevated temperatures. Consequently, the metal must be protected from atmospheric contamination. This can be provided by shielding the metal with welding grade inert gas. The present work describes the application of TIG arc welding to titanium and investigated the effect of welding parameters like weld current, weld gap and gas flow rate on mechanical properties of welded joints of unalloyed commercially pure titanium Gr-2 materials. Taguchi optimization method has been used to find out optimal setting of parameters for weld joints characterization. The welded joints showed maximum ultimate tensile strength of about $429 \mathrm{MPa}$ with percentage elongation of $23.33 \%$. A significant grain coarsening has noticed in the fusion zone consisting of $\alpha$-phase in different direction bounded by $\beta$ phase. The hardness value at fusion zone and base metal are typically observed to be $235 \mathrm{HV}$ and $145 \mathrm{HV}$ respectively.
\end{abstract}

KEYWORDS. TIG welding; Titanium Gr-2; Weld parameters; Weld characterization.

\section{OPEN ACCESS}

Citation: Patil, H. S., Patel, D. C., Patil, C. S., Characterizations of TIG welded joints of unalloyed commercially pure titanium Gr-2 for weld process parameters, Frattura ed Integrità Strutturale, 48 (2019) 377-384.

Received: 18.12 .2018

Accepted: 23.02.2019

Published: 01.04.2019

Copyright: (C) 2019 This is an open access article under the terms of the CC-BY 4.0, which permits unrestricted use, distribution, and reproduction in any medium, provided the original author and source are credited.

\section{INTRODUCTION}

he high strength, low weight ratio and outstanding corrosion resistance inherent to titanium and its alloys has led to a wide and diversified range of successful applications which demand high levels of reliable performance in surgery and medicine as well as in aerospace, automotive, chemical plant, power generation, oil and gas extraction, sports, and other major industries. 
In the majority of these and other engineering applications titanium has replaced heavier, less serviceable or less cost effective materials. Designing with titanium taking all factors into account has resulted in reliable, economic and more durable systems and components, which in many situations have substantially exceeded performance and service life expectations. Titanium is available in different grades, unalloyed or alloyed.

Unalloyed Commercially Pure (CP) Titanium is available in four different grades, 1, 2, 3 and 4, which are used based on the corrosion resistance, ductility and strength requirements of the specific application. Grade 1 has the highest formability, while Grade 4 has the highest strength and moderate formability. CP Titanium users utilize its excellent corrosion resistance, formability and weldable characteristics in many critical applications. Titanium Grade 2 is stronger than Grade 1 and equally corrosion-resistant against most applications. Titanium Grade 2 is typically used for orthopedic applications, such as implants and prosthesis; airframe and aircraft engine parts; marine chemical parts; condenser tubing; heat exchangers. Titanium Grade 2 may be welded by a wide variety of conventional fusion and solid-state processes, although its chemical reactivity typically requires special measures and procedures.

Szymlek has reviewed joining methods for titanium and steel materials by means of explosive welding i.e.by TIG and brazing process and also analyzed FSW analysis of titanium with the use of copper and tantalum or vanadium interlayer [1]. For welding of titanium and its alloys with precise and high quality weld, tungsten inert gas welding (TIG) is ideally suitable. In improving the mechanical properties of the weld, high depth of penetration and low heat affected zone (HAZ) plays an important role [2].

However, the relatively shallow penetration capability and low productivity are the main limitations in the TIG welding process. Attaining full penetration of welds with superior mechanical properties in single pass weld the notable technique was to use activating flux with TIG (A-TIG) welding process [3]. Wang has been used micro-plasma arc welding to weld ultra-thin titanium plates. It is widely used in manufacture of thin-walled titanium tubes, automobile parts, medical and other industrial fields, is an excellent structural material [4]. Krishnanunni studied the effect of welding condition like shielding gas flow rate and numbers of weld passes on hardness of pure titanium material by butt TIG welding [5]. Ugur investigated the multi-response optimization of tungsten inert gas welding (TIG) process for an optimal parametric combination to yield favorable bead geometry of welded joints using the grey relational analysis and taguchi method [6]. Chen discussed the friction stir welding on commercially pure titanium with $\mathrm{ADC1}_{2}$ cast aluminum alloy using WC-Co tool. Defects arise due to insufficient flow of Ti, causes inhomogeneous distribution. Also due to lower heat input and low reaction time for $\mathrm{Ti}$ and $\mathrm{Al}$, decrease in tensile strength was observed [7]. The modified butt joint configuration was employed into the FSW of Ti-6Al-4V alloy to Al-6Mg alloy with a special pin plunge setup by Zhang [8]. The results reveal that the joint mechanical tensile strength can reach more than $92 \%$ of the parent aluminium alloy strength. Kato has stated that Titanium (Ti/Ti) rods and titanium and stainless steel (Ti/SS) rods has been joined by diffusion welding under phase transformation in an air atmosphere [9]. The effect of halide fluxes $\left(\mathrm{NaCl}\right.$ and $\left.\mathrm{CaCl}_{2}\right)$ and welding parameters on welding of Ti-6Al-4V was investigated by Pujari Rao to find optimal setting of parameters for weld penetration and heat affected zone (HAZ). All the parameters on 2-way and 3-way interaction on penetration and interactions on HAZ were found to have significant effect [10]. Zuhailawati has studied the shear strength and micro-structural characteristics of the spot brazed titanium and nickel base metal with and without addition of filler metal by spot resistance welding [11]. Akman has studied about (Ti-6Al-4V) titanium alloys welded by laser welding and found that, the ratio between the pulse energy and pulse duration was the most important parameter in defining the depth of penetration also noted that variation of pulse duration at constant peak power has no influence on the depth of penetration [12].

\section{MATERIALS \& EXPERIMENTAL METHODS}

$\mathrm{U}$

nalloyed commercially pure titanium Gr-2 sheets are used in this study. The chemical composition and mechanical properties of CP titanium is presented in table- 1 and table-2. The dimension of each weld specimen was set $100 \mathrm{~mm} \times 75 \mathrm{~mm}$ with thickness of $3 \mathrm{~mm}$.

\begin{tabular}{crcccc}
\hline $\mathrm{C}$ & $\mathrm{Fe}$ & $\mathrm{O}$ & $\mathrm{N}$ & $\mathrm{H}$ & $\mathrm{Ti}$ \\
$<0.08 \%$ & $<0.3 \%$ & $<0.25 \%$ & $<0.03 \%$ & $<0.015 \%$ & Balance \\
\hline
\end{tabular}

Table 1 Chemical specification of workpiece material. 


\begin{tabular}{llll}
\hline Yield Strength & Ultimate Tensile Strength & Elongation & Reduction of Area \\
$275 \mathrm{MPa}$ & $345 \mathrm{MPa}$ & $>20 \%$ & $>30 \%$ \\
\hline
\end{tabular}

Table 2 Mechanical properties workpiece material.

The TIG welding operations were performed on the TIG weld machine with argon of $99.99 \%$ purity used as shielding gas. For uniformity titanium filler rod with $2 \mathrm{~mm}$ diameter was selected, as its composition was same as the composition of workpiece material as shown in table 1 . Air-cooled torch with a titanium electrode rod with a 2 mm diameter was used. The electrode tip was of blunt point with a $45^{\circ}$ angle. A direct-current, electrode-negative power supply device was used with a mechanized operation system in which the welding torch travelled at a constant speed. Single-pass, manual TIG welding was performed along the longitudinal centerline of the test specimen to produce a weld on a strip.

The samples to be TIG welded were polished with 400 grit (silicon carbide) flexible abrasive paper to remove surface impurities and then it was cleaned with acetone. The welding of C.P titanium are conducted using GTA welding machine with air cooled torch head, as indicated in figure-1(a). Welded joints samples of CP titanium for different weld process parameters are shown in figure 1(b).

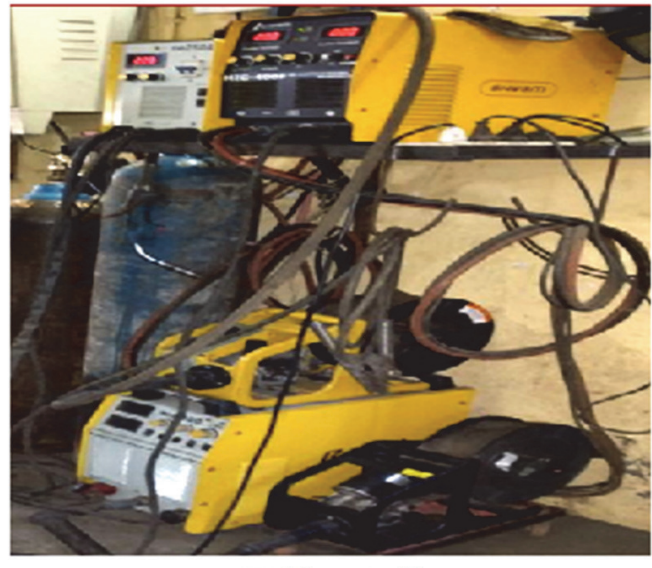

(a) Welding Machine

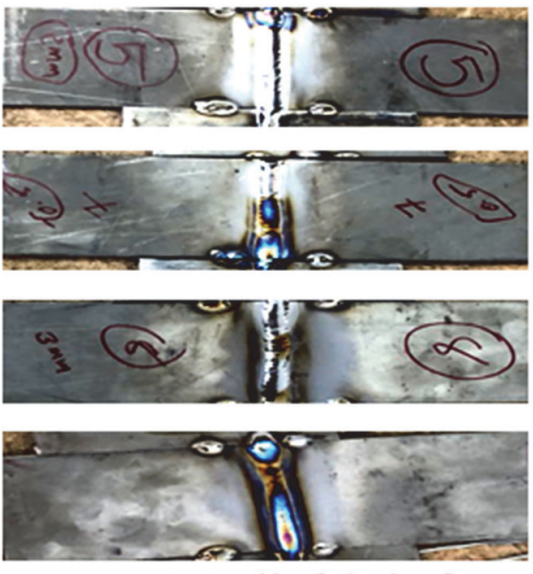

(b) TIG V-welds of Titanium for different process parameters

Figure- 1: Experimental setup and TIG welded joints for different parameters

The welding parameters considered for this investigation were weld current, weld gap and gas flow rate on $\mathrm{V}$-welding of CP Titanium materials with 3 levels each as shown in table 3.

\begin{tabular}{lccc}
\hline Welding Parameters & Level 1 & Level 2 & Level 3 \\
Welding Gap(mm) & 0.5 & 0.75 & 1 \\
Gas flow Rate(lit/min) & 20 & 25 & 30 \\
Current(A) & 90 & 95 & 100 \\
\hline
\end{tabular}

Table 3: Control parameters and their levels

Taguchi method is a statistical method developed by Taguchi and Konishi which involves identification of proper control factors to obtain the optimum results of the process. Orthogonal Arrays (OA) are used to conduct a set of experiments and these experiments are used to analyze the data and predict the quality of weld joints produced. Here, an attempt has been made to demonstrate the application of Taguchi's Method to improve the weld quality and properties of weld components. Welding quality also affects the life of titanium material joint and hence it is desirable to obtain higher quality of welding. The most suitable orthogonal array for experimentation is L9 array as shown in table-4. 


\begin{tabular}{ccccc}
\hline $\begin{array}{c}\text { Welding } \\
\text { Specimen }\end{array}$ & $\begin{array}{c}\text { Welding } \\
\text { Current(A) }\end{array}$ & $\begin{array}{c}\text { Voltage(V) } \\
1\end{array}$ & $\begin{array}{c}\text { Welding } \\
\text { Gap(mm) }\end{array}$ & $\begin{array}{c}\text { Gas Flow } \\
\text { Rate(lit/min) }\end{array}$ \\
2 & 90 & 95 & 0.5 & 20 \\
3 & 100 & 95 & 0.75 & 25 \\
4 & 90 & 95 & 0.75 & 30 \\
5 & 95 & 95 & 1 & 25 \\
6 & 100 & 95 & 0.5 & 30 \\
7 & 90 & 95 & 1 & 20 \\
8 & 95 & 95 & 0.5 & 25 \\
9 & 100 & 95 & 0.75 & 30 \\
\hline
\end{tabular}

Table 4: Orthogonal array L9

\section{RESULT AND DISCUSSION}

\section{Radiograpby Analysis}

$\mathrm{B}$ y using Radiographic unit, X-Ray radiographic inspection was carried out on weld samples as per radiography standard methods ASME section-VIII Div-I. In radiographic test 30Ci \& Iridium Ir192 was used as radioactive source. The RT Technique was S.W.S.I. with sensitivity of $2 \%$ and 5 minutes of developing time. The film used was Agfa D-4 and the radiographs indicated welds with different defects. The table-5 indicated concluding radiography observations and remarks of the welded joints.

\begin{tabular}{cccccc}
\hline $\begin{array}{c}\text { Weld } \\
\text { Specimen }\end{array}$ & $\begin{array}{c}\text { Welding } \\
\text { Current }\end{array}$ & $\begin{array}{c}\text { Gas Flow } \\
\text { Rate }\end{array}$ & $\begin{array}{c}\text { Welding } \\
\text { Gap }\end{array}$ & Observation & Remarks \\
1 & 90 & 20 & 0.5 & Porosity & Acceptable \\
2 & 90 & 25 & 0.75 & Porosity & Acceptable \\
3 & 90 & 30 & 1 & Lack of Penetration & Rejected \\
4 & 95 & 20 & 0.75 & Lack of Fusion & Acceptable \\
5 & 95 & 25 & 1 & No Significant Defects & Acceptable \\
6 & 95 & 30 & 0.5 & Porosity/Lack of Penetration & Rejected \\
7 & 100 & 20 & 1 & Porosity & Acceptable \\
8 & 100 & 25 & 0.5 & Porosity & Acceptable \\
9 & 100 & 30 & 0.75 & Porosity/ Lack of Fusion & Reject \\
\hline
\end{tabular}

Table- 5: Radiography observation/remarks of v-joints

The presence of porosity, lack of penetration and fusion in TIG welded joints was observed in Ti-Gr2. The low density of titanium alloys enables the in depth of penetration of radiation in welded structures, allowing for the observation of porosity.

\section{Tensile Properties ANALysis}

$\mathrm{T}$ ensile tests have conducted on universal testing machine to determine the yield strength and ultimate tensile strength of the welded specimens. The specimens used for tensile testing were cut from welded samples using water jet machine. The dimension of tensile specimen as per ASTM-E8 has been represented by figure-2. 


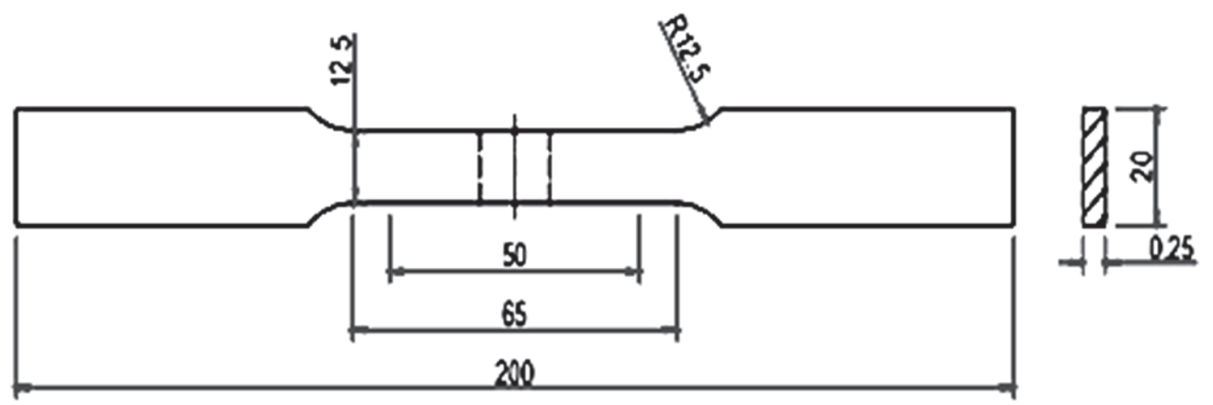

Figure 2: Tensile test specimens for welded samples

The tensile properties of welded titanium for different joints were measured at room temperature. The welded joints have mechanical properties like in the range of yielding strength of 190-339.23 MPa, ultimate tensile strength of 318.46$429 \mathrm{MPa}$ and percentage elongation of $6.66 \%-26.66 \%$. The stress-strain curves for weld samples with various weld process parameters have been shown in figure-3. The weld sample-5 exhibited good mechanical properties than other weld samples. These results indicate that the ultimate tensile strength of welded joints is higher than the yield strength, which indicates a noticeable work hardening beyond the yielding.

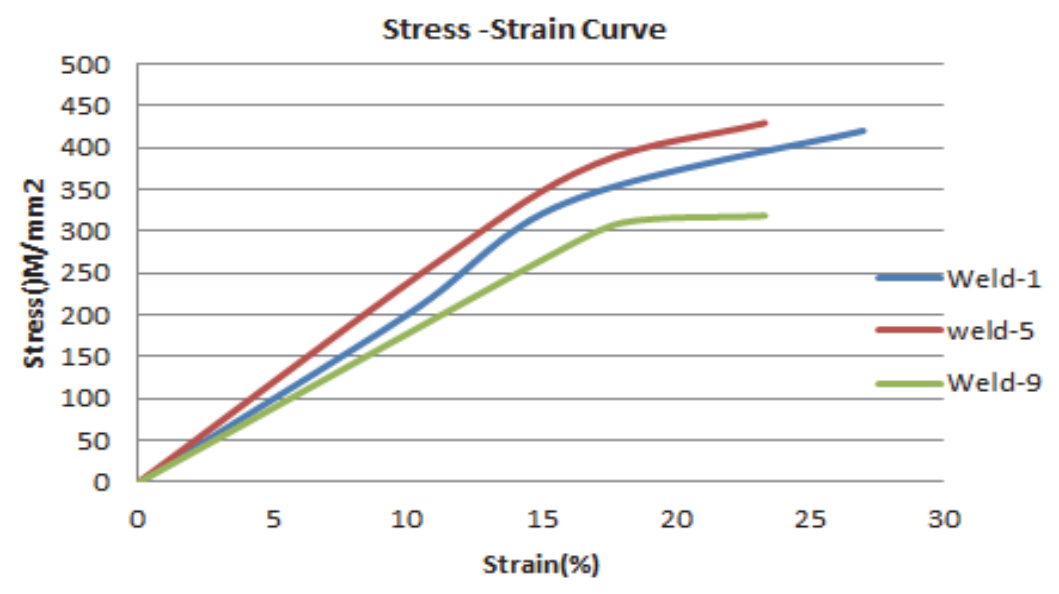

Figure 3: Tensile test specimens for welded samples

\section{Weld Microstructure Analysis}

The samples for optical microscopy were cut into the size of $30 \mathrm{mmx} 25 \mathrm{mmx} 3 \mathrm{~mm}$ and pieces were polished using 100 , 150, 220, 400, 600 grit silicon carbide paper. Etching procedures were used to expose the underlying microstructural features. Solutions used for etching titanium include a fresh Keller etchant with composition $5 \mathrm{ml} \mathrm{HNO}$, 3ml HCL, 2ml $\mathrm{HF}$ and $190 \mathrm{ml}$ distilled water. The polished metallographic mount was etched in the solution from 40 to 50 seconds to reveal the microstructural features. The variation of microstructures/grain structures of various welded samples and C.P titanium has been shown in figure 4.

Figure 5(a) shows the optical micrographs weld jointed commercially pure titanium moving from the base metal (BM) to the fusion zone (FZ) through the heat affected zone (HAZ). It has observed from the figure-5(b) that the BM microstructure of commercial pure titanium consists of equi-axed $\alpha$-phase grains with the presence of fine and disperses precipitation of $\beta$-phase. Inside the grains structure and in the grain boundary, the fine and disperse precipitation of beta phase has noticed. The interface between the BM and the heat HAZ clearly indicates that the region from where the thermal cycles occurred during the welding process operate originally and usually on the change in microstructure.

Due to this complex thermal cycle, the equiaxed grains had grown in larger size in the HAZ and it has noticed in the figure-5(c). As a result of the welding thermal cycles with a peak temperature, a significant grain coarsening is noticed in the FZ which consists of $\alpha$-phase in different direction bounded by $\beta$-phase as depicted in figure 5 (d). In comparison to the microstructure of the heat affected zone, an inhomogeneous growth of microstructure at the fusion zone has 
observed. Based upon the cooling rate and stabilizing agent, the microstructures are grown at fusion zone. Structural morphology of C.P. titanium sheet is altered with respect to heat input consisting of $\alpha$-phase bounded by $\beta$-phase and it is evident in Fig. 6.
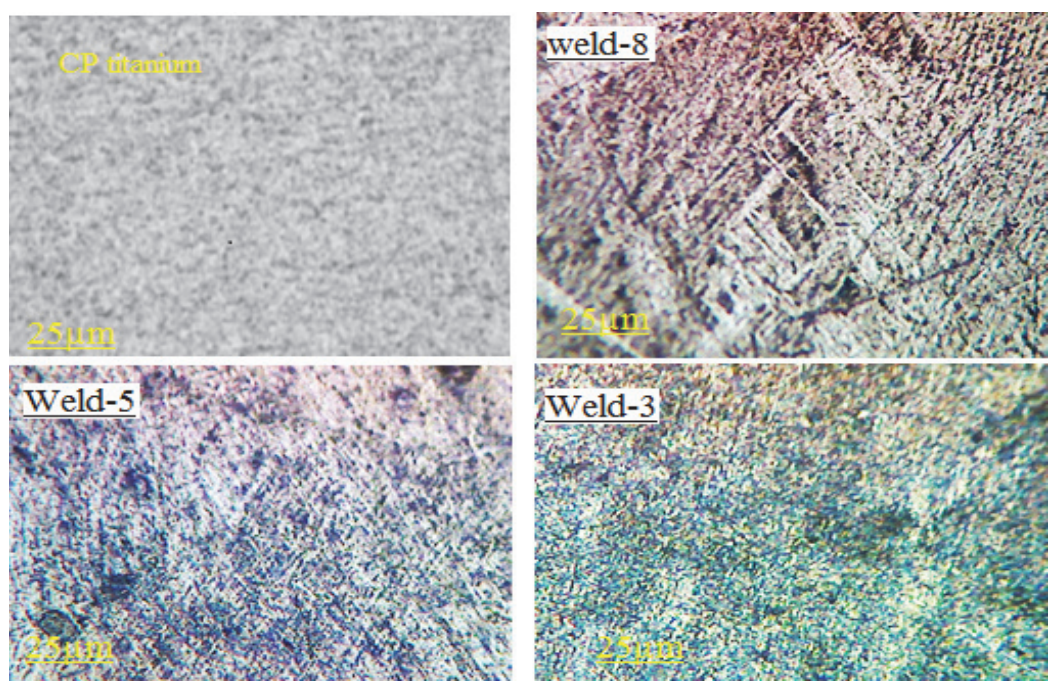

Figure 4: Microstructures structures of C.P titanium and various TIG welded samples.
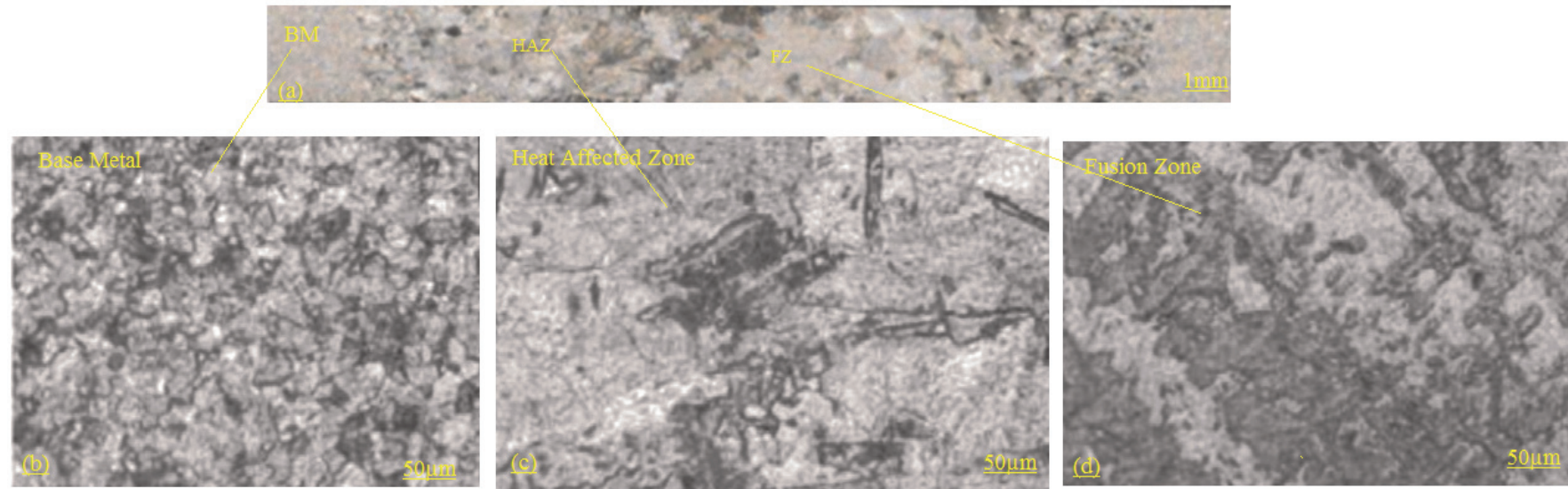

Figure 5: (a) optical micrographs of TIG weld profile of Titanium Gr-2, and (b-d) optical micrographs showing grain structures in the BM, HAZ and FZ

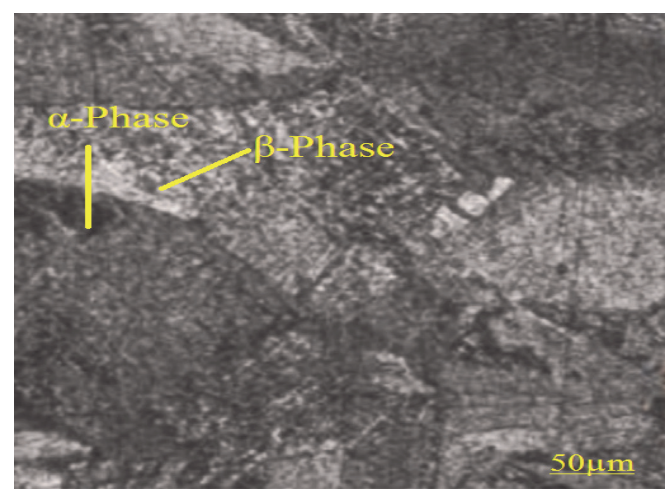

Figure 6: Fusion Zone Microstructures for Titanium welds. 


\section{HARDNESS PROPERTIES ANALYSIS}

$\mathrm{F}$ ig. 7 shows the hardness variations (across the weld) from the center of fusion zone to the base metal for various sample welded at different parameters for $3 \mathrm{~mm}$ thickness joints. These hardness values have some fluctuations along the fusion zone to base metal. This is due to the irregular grain growth and inherent variations of the alpha beta phases in the microstructure of the weldment of C.P titanium material. This behaviour is also due to the slow cooling rate of TIG weld process. The maximum value of hardness at the fusion zone has found $235 \mathrm{HV}$ (for sample 5) and minimum value of $175 \mathrm{HV}$ (for sample 9). As expected, the hardness value increased with increasing cooling rate i.e. low heat input due to the formation of an increasingly finer transformed structure. In addition, the hardness of the fusion zone increases with decrease in heat inputs. Based on the micro-hardness test, it is evident that the weld provides good strength than the base metal due to the hardness in the fusion zone which is relatively higher than the hardness of the base metal.

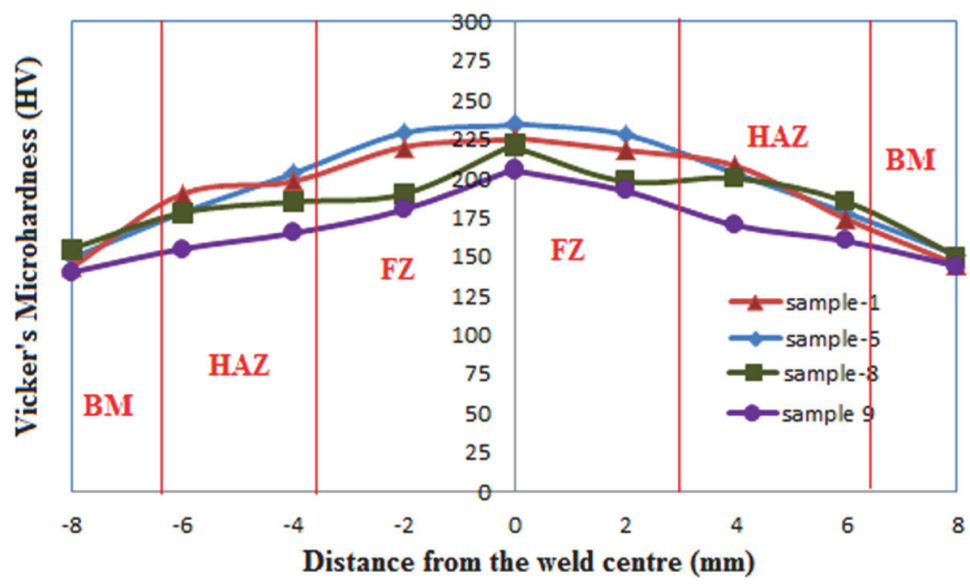

Figure 7: Hardness profile showing hardness in the BM, HAZ and FZ

\section{CONCLUSION}

B ased on available literature and the results drawn from this investigation in TIG welding of C.P titanium materials, the conclusions are:

Welding parameters like welding current, weld gap and gas flow rate are optimized and established from bead-on plate trials for full penetration $V$ welds.

In the fusion zone, a significant grain coarsening size is noticed consisting of alpha phase in different direction bounded by beta phase.

In HAZ, equiaxed grains had grown larger in size compared to grains in base metal. As a result, the degree of grain coarsening decreases as one move from the fusion zone to the base metal.

Tensile test illustrates that the yield and ultimate strengths of the joints rises above the base metal and in actual fact all failures occurred in the base metal area.

Furthermore, percentage of elongation decreases in the order of fine grain microstructure due to the decreased heat input. It also seen that, hardness values are having some fluctuation because of variation in grain structures.

The optimized weld sample 5 with weld parameters- Current-95A, Gas flow-25lit/min, wed gap- $1 \mathrm{~mm}$ has good mechanical properties with respect to other weld samples.

\section{REFERENCES}

[1] Szymlek, K. (2008). Review of titanium and steel welding methods, Advances in Materials Science, 8(1), pp. 186-194.

[2] Pal, S., Pal, S.K., Samantaray, A.K. (2010). Determination of optimal pulse metal inert gas welding parameters with a neuro-GA technique, Materials and Manufacturing Processes, 25, pp. 606- 615. 
[3] Tseng, K.H., Hsu, C.Y. (2011). Performance of activated TIG process in austenitic stainless steel welds, Journal of Materials Processing Technology, 211, pp. 503-512.

[4] Xin Wang, F., Ping He, J., Qiang Fang, J., Xiang, F., Lei Ren, L. (2012). Study of titanium foil welding using microplasma arc welding, Advanced Materials Research, 538 - 541, pp.1469-1472.

[5] Krishnanunni, (2011). Effect of welding conditions on hardness of commercially pure titanium. Int. J. Technol., 3(2), pp. 19-24.

[6] Ugur Esme, S. O., Bayramoglu, M., Kazancoglu, Y. (2009). Optimization of weld bead geometry in TIG welding process using grey relational analysis and taguchi method, Materials Technology, 43(3), pp. 143-149.

[7] Chen, Y.C., Nakata, K. (2009). Microstructural characterization and mechanical properties in friction stir welding of aluminum and titanium dissimilar alloys, Materials and design, 30, pp. 469-474.

[8] Li B., Zhang Z., Shen Y., Hub W., Luo L., (2014). Dissimilar friction stirs welding of Ti-6Al-4V alloy and aluminum alloy employing a modified butt joint configuration: Influences of process variables on the weld interfaces and tensile properties, Materials and design, 53, pp. 838-848.

[9] H. Kato, M. Shibata, K. Yoshikawa, (1986). Diffusion welding of $\mathrm{Ti} / \mathrm{Ti}$ and $\mathrm{Ti} /$ stainless steel rods under phase transformation in air, Materials Science and Technology, 2(4), pp. 405-409.

[10] Srinivasa Rao, P., Raju, P., Kodanda Rama Rao, Ch., Priyangeli, S. P. (2016). Effect of halide fluxes and welding parameters on penetration and HAZ of titanium alloy, JPE, 19(1), pp.81-86

[11] Zuhailawati, H., Saeed, A. M., Ismail, A. B., Samad, Z., Ariga, T. (2010). Spot resistance welding of a titanium/nickel joint with filler metal, Welding Journal, 89, pp. 101-104

[12] Akman, E., Demir, A., Canel, T., Sinmazcelik, T. (2009). Laser welding of Ti-6Al-4V titanium alloys, Journal of Materials Processing Technology, 209, pp. 3705-3713. 